\title{
The causal relationship between parental involvement and children's behavioural adjustment to KG-1 schooling
}

\author{
Masood Badri ${ }^{1,2^{*}}$, Amal Al Qubaisi ${ }^{2}$, Asma Al Rashedi $^{2}$ and Guang Yang ${ }^{2}$
}

\author{
* Correspondence: \\ masood.badri@adec.ac.ae \\ ${ }^{1}$ Abu Dhabi Education Council and \\ UAE University, Al Ain, UAE \\ ${ }^{2}$ Abu Dhabi Education Council and \\ UAE University, Abu Dhabi, UAE
}

\begin{abstract}
The study reports on the relationships between parent involvement and school adjustment behaviours that contribute to the broader constructs of hyperactivity, internalizing and externalizing behaviours for children attending KG-1 public schools across the Emirate of Abu Dhabi. Confirmatory factor analysis and structural equation modelling identify factors that contribute to constructs of hyperactivity, internalizing and externalizing behaviours. The analysis identifies the relative contribution of each of these factors to the adjustment domain of problem/maladaptive behaviour. The study also tests the effect of the parental involvement dimension on the three behaviour constructs. The results of structural equation modelling demonstrate that parental involvement significantly contributes to a decrease of the undesired aspects related to externalizing, internalizing and hyperactivity behaviours. The highest influence is observed for reducing 'arguing with others, acting sad or depressed and being easily distracted'. The most significant driver of parental involvement is parents speaking with teachers on a regular basis. In general, student gender does not influence children's behaviour adjustment.
\end{abstract}

Keywords: Abu Dhabi; Children's adjustment; Externalising behaviours; Hyperactivity behaviours; Internalising behaviours

\section{空

\section{Background}

Parental involvement in school has emerged as an important issue in children's functioning in school. In general, research demonstrates that parental involvement in children's education is a major predictor of school success and exerts a powerful impact on school attainment and adjustment (Kirkhaug et al. 2013; Desforges and Abouchaar 2003; Weiss et al. 2009; Schwartz et al. 1999). Research demonstrates that children with high levels of hyperactivity and impulsive behaviour in the first year of school (reception) had significantly lower levels of academic achievement and progress 3 years later at the end of grade 2, (Becker et al. 2012; Merrell and Tymms 2001). Given the pervasiveness of school adjustment problems having lasting or cumulative effects and the potential costs to the individual and to society, there is a need to study early school adjustment, to identify and understand the behaviours that contribute to children's adjustment and to put in place strategies to promote these skills.

(c) 2014 Badri et al.; licensee Springer. This is an Open Access article distributed under the terms of the Creative Commons Attribution License (http://creativecommons.org/licenses/by/4.0), which permits unrestricted use, distribution, and reproduction in any medium, provided the original work is properly credited. 
Previous research on parental involvement in school has focused largely on academic achievement, with less attention given to its association with the different behaviour domains of child adjustment to school (Kirkhaug et al. 2013; Nokali et al. 2010). To address this gap, the present study examines teacher-rated parental involvement in KG-1 and its association with child behaviour adjustment of externalizing, internalizing and hyperactivity behaviour factors.

The authority responsible for Abu Dhabi public and private schools is the Abu Dhabi Education Council (ADEC). Since the start of ADEC's reform journey in 2008, many international education advisors were invited to shed light on the challenges faced by the system. For KG and preschool, advisors stressed that behaviours identified as predicting certain adjustment difficulties in the West may be viewed differently in Abu Dhabi and thus may serve different functions. Many suggested that an investigation of the relations between externalizing, internalizing and hyperactivity behaviours and social and psychological adjustment, particularly from a developmental perspective, would provide valuable information about the significance of the behaviours in cultural contexts. It was also suggested that parental involvement in those levels of schooling has significant effects on children's adjustment behaviours. The main purposes of the present study using an Abu Dhabi sample are to (1) examine the factor structures of behaviour adjustment (internalizing and hyperactivity behaviours) and parental involvement and (2) to test for associations between parental involvement and student's behaviours as rated by teachers.

\section{Review of literature}

For children, one of the most important transitions is that from a preschool programme to kindergarten, when behaviour is shaped and attitudes are formed that will influence children throughout their education and where children's transitions are most strongly influenced by both home involvement and school environment (Riedinger 1997). Research demonstrates that children have moderate to serious problems transitioning to kindergarten (Pianta and Cox 1998). The same authors note that a discrepancy seems to exist between the expectations of teachers and the actual skills of kindergarten children.

There is a need for kindergarten teachers to collaborate with parents (Pianta and Cox 1998). School readiness reflects a range of dimensions, such as a child's health and physical development, social and emotional development, approaches to learning, language and communication skills and cognitive and general knowledge (McClelland and Morrison 2003; California Department of Education 2000).

For both policy and practice, it is important to know children's characteristics at school entry level. What a child knows and how he or she behaves are products of both genetic endowment and the child's experiences before entering school (Willerman 1979; Plomin 1990). Measures of children's behaviour at school entry can serve as indicators of how well families prepare children for school. These measures provide guidance about what kind of curriculum might be appropriate for the first year of school (Freeman and Hatch 1989; Knudsen-Lindauer and Harris 1989).

Behaviours that contribute to measures of externalizing and internalizing behaviour and hyperactivity may impede children's adjustment to school (Margetts 2005). An awareness of these observable behaviours can assist early childhood staff in preschools and the early years of schooling to identify children who may be at risk of adjusting 
poorly to school. Research suggests that children who make a satisfactory initial adjustment to school are more likely to be successful in their future progress than those who have difficulty adjusting to the school environment (Belsky and MacKinnon 1994; Cowan et al. 1994; Kienig 2000; Hoover-Dempsey and Sandler 1997).

The transition from a familiar situation into a new or unfamiliar situation - for example, from home to childcare/preschool, to primary school, or secondary school - is characterized by change, tensions and uncertainties (Cowan et al. 1994; Dockett et al. 1997; Fabian 2000b). A child's sense of being is often challenged by the new and unfamiliar (Dunlop 2000). Children face a new environment of buildings and classrooms, new school-wide and teacher expectations, new academic challenges and acceptance into a new peer group (Margetts 2005). They must function independently, develop relationships with staff and peers and behave in ways that are appropriate for their class and school, including conforming to rules (Cowan et al. 1994; Dockett et al. 1997; Fabian 2000a; Margetts 2003).

Adjustment to school receives support from a number of skills, including social competence, problem solving, self-reliance and determination, knowing about 'not knowing' and what to do about it, behavioural control and academic competence (Fabian 2000b; Margetts 2002). Children are at risk of not adjusting easily to school when a mismatch exists between the personal and cultural skills, attitudes and knowledge they bring to school and the expectations of the school itself (Clancy et al. 2001; Fabian 2000b; Margetts $2003,2005)$. The stress associated with the changes and challenges of starting school can manifest itself in maladaptive or problem behaviours (Creasey et al. 1995). Many suggest that reactions such as anxiety, avoidance or negative attitudes are expected during transitions, but they may also signal early adjustment difficulties (Margetts 2005; Prior 1996). Some also suggest that children's rapid adjustment to school can overcome much of the potentially negative effects on children's confidence and school behaviour (Belsky and MacKinnon 1994). The concern then is for children in whom these negative responses persist. Margetts (2002) notes that children who are non-compliant, disorganized, distractible or antisocial are more likely to experience adjustment difficulties than other children. Others note that it is the ongoing early behavioural difficulties that are of concern (Belsky and MacKinnon 1994; Cowan et al. 1994; Taylor 1998). Problem behaviours in the early years, including extreme overactivity, inability to sit still, short attention span, emotional difficulties and negative attitude have predicted behaviour problems in adolescence (Caspi et al. 1995). However, it should be added that there are different viewpoints about what is considered 'problem' behaviour during early years. For example, some of the behaviours (e.g., short attention span and not being able to sit still) may not actually be problem behaviours during early years (Ekblad 1990; Behar and Stringfield 1974).

\section{Identifying behavioural responses to starting school}

Measures of adjustment in terms of behaviour include constructs or domains related to internalizing and externalizing behaviours (Lycett et al. 2014; Caldwell and Pianta 1991), anxiety, avoidance and negative attitudes in class (Moser et al. 2014; Ladd and Price 1987), accepting and conforming to the demands of classroom routine and organization (Renwick 1984), restlessness, fidgeting and poor concentration (Dougherty et al. 2011; Rydell 1989). Teachers and parents comment that children are hyperactive 
or aggressive or withdrawn but have difficulty defining particular behaviours that contribute to these broad constructs (Margetts 2005).

The Social Skills Rating System (SSRS; Gresham and Elliott 1990) is a multirater norm-referenced instrument designed to identify social competence and adaptive behaviour in children across three domains - social skills, problem behaviours and academic competence. The social skills domain includes the sub-domains of co-operation, assertion, responsibility, empathy and self-control. The problem behaviour domain includes the sub-domains of externalizing problems, internalizing problems and hyperactivity. The literature suggests that these SSRS domains and sub domains are appropriate measures of adjustment (Margetts 2005). In the SSRS, the latent variable, externalizing behaviour, is measured using six observable items including 'fights with others' , 'threatens or bullies others', 'gets angry easily' and 'has temper tantrums'. Margetts (2005) obtained data using the problem behaviour domain (items 31 to 48), of the SSRS (teacher form) (elementary level) which included the subscales of externalizing behaviour, internalizing behaviour and hyperactivity. Each item is rated using 3-point Likert-type scales to indicate the frequency of specific behaviours, 0 for 'Never', 1 for 'Sometimes' and 2 for 'Very often'.

Identifying parental involvement responses for KG-1

There is no universal agreement on what parental involvement entails. It can take many forms, from involvement at the school (as a director or helping in the classroom or during lunch breaks) through home-based activities such as reading to the child, teaching songs or nursery rhymes and assisting with homework. Most studies focus on parents' involvement in the life of the school and their involvement in support of the individual child at home.

Parental involvement with the school and teachers has been found to improve children's academic achievement and social functioning at school (Hattie 2009; Jeynes 2007). Parental involvement in school activities is reported to cause improved behaviour and attitudes, better emotional adjustment and greater well-being (Hornby and Witte 2010) and improved social competence (Hill and Craft 2003). Some research suggests that positive bonding between parent and school is a predictor of later social and academic success for young children (Reid et al. 2007; Semke et al. 2010). Epstein (2001) describes types of parental involvement that reflect different co-operative relationships between schools and parents, including parenting, communicating with the school and learning at home. Teachers and parents are considered partners, with separate and shared tasks and responsibilities varying according to the level of parental involvement. Parental involvement may be both school- and parent-initiated (Driessen et al. 2005; Fantuzzo et al. 2000).

Research describes several parental involvement instruments used in empirical studies. The items in the surveys have largely reflected various co-operative relationships between schools and parents, specifically, parenting, communicating with the school, volunteering, learning at home, decision-making in the school and collaborating with the community. The measures were consistent with the six types of measures addressed by Epstein (2001). Other measures of parental involvement usually assess the frequency and quality of the contact between parents with teachers as well as their participation in school functions and activities, both in school and at home (Dearing et al. 2006; Machen et al. 2005). Most of the research sought to identify the effect of parental 
involvement on student outcomes. However, other parental involvement studies and those on children in general examined the relationship of parental involvement in school activities on improved behaviour, attitudes and attendance at school, as well as better emotional adjustment and greater well-being (Drugli et al. 2011; Kirkhaug et al. 2013; Catsambis 2001; Hill and Craft 2003; Hornby and Witte 2010).

\section{Behavioural responses and children's gender}

Several previous studies have analysed children's gender and other socio-demographic variables to relate them to parental involvement or behavioural adjustments (Rogers et al. 2009; Duckworth 2008; Muller 1998). In their study, Stemmler et al. (2005) found that four out of six predictors showed significant longitudinal correlations. For boys, physical aggression, destroying things/delinquency, hyperactivity/inattention, and externalizing problems correlated positively with problematic classroom behaviour. Hyperactivity/inattention was the best single predictor followed closely by the general scale on externalizing problems.

Williford et al. (2007) noted that externalizing problems are more prevalent among boys than girls as boys seem to be more hyperactive, more often demonstrate oppositional behaviour. Some studies found that boys tend to manifest higher rates of externalizing problems than girls (Krishnan 2011; Prior et al. 1993).

The present study will also test the effect of children's gender on variables of both behaviour and parental involvement. Because teachers are among the first to recognize and appreciate parental involvement, it is acceptable to rely upon teacher ratings as the main measures of both children's behavioural adjustment and parental involvement (Kirkhaug et al. 2013; Jeynes 2003).

\section{Methods}

\section{Developing the study instrument}

For the Abu Dhabi study, it was important to ensure that KG-1 teachers have sufficient knowledge to rate the items. Although other studies utilize many scales of parental involvement, this study used a focus group to identify parental involvement items to ensure that the survey teachers were familiar enough with the items. As a result, for the purpose of this study, and from the review of literature, a list of parent involvement items for the questionnaire was prepared. The measurement originally consisted of 22 items. A focus group of eight (KG-1) teachers from Abu Dhabi discussed the items. The group focused primarily on whether teachers can adequately assess the parent involvement degrees for each item. Following the discussion, a short questionnaire was sent by email to 100 ADEC (KG-1) teachers. A total of 73 teachers answered the survey, which took only 5 min to complete. Each teacher was asked, 'How comfortable are you in indicating how knowledgeable you are about each of the items related to parent involvement?' on a scale from ' 1 : Not familiar at all' to ' 5 : Totally familiar'. Only six items received a mean score of 3 or above: parents (1) read more to their children at home, (2) are more likely to visit their child's classroom, (3) are highly involved in child education, (4) speak to the teacher regularly, (5) support their children's learning at home and (6) exhibit strong patterns of involvement.

It should be added that a post focus group of several principals discussed the perception of teachers of the six items and how they could be subjective and biased about replaying 
to them. The discussions focused on the assumption that teachers might not be informed fully about some of those items. However, and during the discussions, many teachers raised the points that KG teachers are encouraged by the school principals, vice principals and ADEC advisors to use different means in understanding better on the degree of occurrences of these items at home. Some teachers directly contact parents and discuss these matters. Many teachers talk to individual students on related matters to better understand the occurrences of these items. In addition, most professional developments provided to teachers focus on how to better seek understanding of these issues. In short, teachers know all six items related to parental involvement to a large degree. As a result, for parental involvement, the survey included only these six items.

The study instrument used a scale ranging from 1 to 5 , with a higher score indicating a higher degree of agreement, that is, parent involvement. As a result, the additional factors related to parent involvement and perception of student performance is numbered from B51 to B57. For the current study, a 5-point Likert-type scale serves this purpose ( 1 for 'Do not agree at all', 2 for 'Do not agree most of the time', 3 for 'Neutral', 4 for 'Agree most of the time' and 5 for 'Agree all the time').

The study utilizes the SSRS as recommended and used by Margetts (2005) to identify items that contribute to the constructs of externalizing, internalizing and hyperactive behaviours in the first year of schooling and to identify the relative contribution of each construct to each behaviour sub-domain. Data were obtained using the problem behaviour domain (items 31-48) of the (SSRS, teacher form, elementary level), which includes the subscales of externalizing and internalizing behaviours and hyperactivity. Teachers were aware of the domain category (problem behaviour) but unaware of the sub-domain categories. The items in the three behaviour constructs use the same numbering scheme as in Margetts (2005), A31 to A48. Table 1 provides a list of each sub-domain item. Figure 1 show the general model used in the study. Unlike Margetts (2005), who used a rating with 3-point Likert-type scales to indicate the frequency of specific behaviours, this study used 5-point Likert-type scales ( 1 for 'Never', 2 for 'Sometimes', 3 for 'Neutral', 4 for 'Most of the time' and 5 for 'All the time').

\section{The sample}

The subjects were 391 children in KG-1 public schools in Abu Dhabi (4-year-old children). The study was conducted during the first semester of the academic year 2013-2014. For the children, 190 (48.6\%) were boys and 201 (51.4\%) were girls. All teachers of related KGs were contacted by email; a total of 59 teachers accepted to participate in the study. About 24 of the teachers were from the UAE or other Arab nationals. The rest were from Western nationalities. Schools were selected on the basis of attendance by significant numbers of children. The schools were mainly located in the cities of Abu Dhabi and Al Ain. Children with disabilities were not included in the study. All teachers were females. Each teacher was asked to randomly select at least five students from their class to be rated on the survey items.

\section{Analysis}

The descriptive statistics (mean and standard deviations) for each item were calculated. Correlation analysis will identify the relationships between the three constructs of externalizing, internalizing and hyperactive behaviours and the teacher perceptions of 
Table 1 Descriptive statistics of items and constructs

\begin{tabular}{|c|c|c|c|}
\hline \multicolumn{2}{|c|}{ Constructs and items } & Mean & Standard deviation \\
\hline \multicolumn{2}{|c|}{ Externalizing behaviour } & 2.96 & 1.069 \\
\hline 31 & Fights with others & 2.63 & 1.280 \\
\hline 33 & Threatens or bullies others & 3.18 & 1.271 \\
\hline 41 & Argues with others & 2.80 & 1.491 \\
\hline 42 & Talks back to adults when corrected & 3.26 & 1.258 \\
\hline 43 & Gets angry easily & 3.11 & 1.368 \\
\hline 44 & Has temper tantrums & 2.17 & 1.271 \\
\hline \multicolumn{2}{|c|}{ Internalizing behaviour } & 2.99 & 1.120 \\
\hline 32 & Has low self esteem & 2.82 & 1.408 \\
\hline 34 & Appears lonely & 3.21 & 1.265 \\
\hline 38 & Shows anxiety about being with a group of children & 2.81 & 1.191 \\
\hline 39 & Is easily embarrassed & 3.36 & 1.425 \\
\hline 45 & Likes to be alone & 3.07 & 1.447 \\
\hline 46 & Acts sad or depressed & 2.71 & 1.420 \\
\hline \multicolumn{2}{|c|}{ Hyperactivity behaviour } & 3.02 & 0.937 \\
\hline 35 & Is easily distracted & 2.99 & 1.276 \\
\hline 36 & Interrupts conversations of others & 2.97 & 1.444 \\
\hline 37 & Disturbs ongoing activities & 3.07 & 1.241 \\
\hline 40 & Doesn't listen to what others are saying & 2.98 & 1.254 \\
\hline 47 & Acts impulsively & 2.90 & 1.094 \\
\hline 48 & Fidgets and moves excessively & 3.23 & 1.319 \\
\hline \multicolumn{2}{|c|}{ Parent involvement } & 3.28 & 0.949 \\
\hline 51 & Parents read more to their children at home & 3.12 & 1.136 \\
\hline 52 & Parents more likely to visit their child's classroom & 3.56 & 1.234 \\
\hline 54 & Parents highly involved in child education & 3.14 & 1.585 \\
\hline 55 & Parents speak to teacher regularly & 3.54 & 1.238 \\
\hline 56 & parents support their children's learning at home & 3.04 & 1.265 \\
\hline 57 & Parent strong patterns of involvement & 3.28 & 1.261 \\
\hline
\end{tabular}

parent involvement and class performance. Correlations between the individual items will also be reported.

Confirmatory factor analysis (CFA) tested the fit of survey items to each sub-domain measure of adjustment. Structural equations modelling tested the overall model fit of behaviour constructs with the parent involvement construct and the teacher's perception

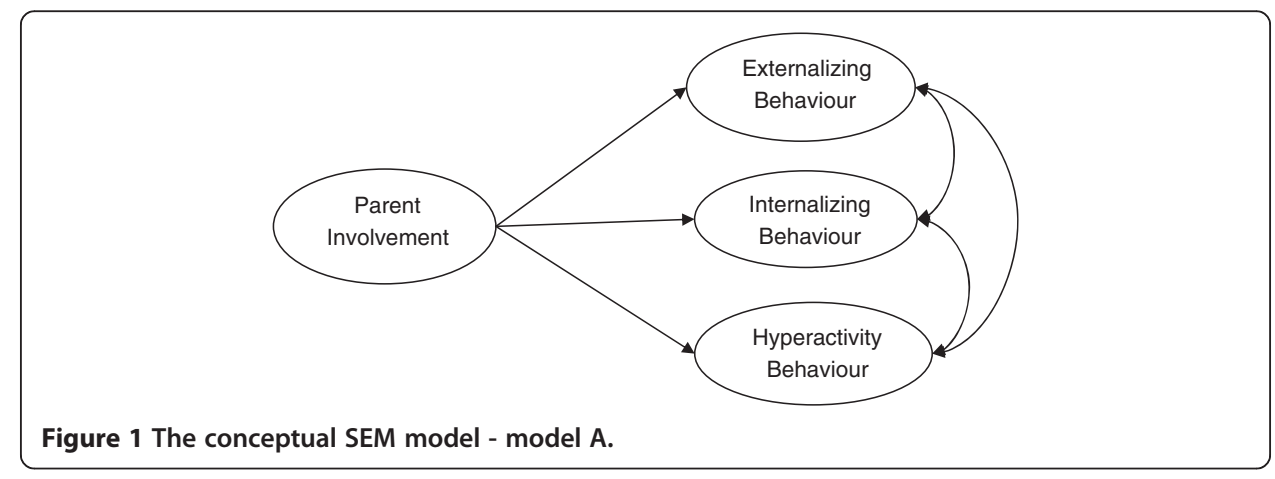


of performance. LISREL 9.03 was used for structural equation modelling (Jöreskog and Sörbom 1989). Having established 'good fitting' models, valid indicators of each latent variable or sub-domain of adjustment to school were identified.

For both CFA and structure equation modelling several fit indexes will be used. Statistical measures of fit included the Chi-square $\left(\chi^{2}\right)$, root mean square error of approximation RMSEA and comparative fit index CFI. A non-significant $\chi^{2}$ suggests that the model fits the data adequately, but $\chi^{2}$ is sensitive to sample size. The CFI determines whether the hypothesized model is a better fit to the data than a null model. CFI values range from 0 to 1 , and $\mathrm{Hu}$ and Bentler (1999) have suggested a minimum cutoff of 0.95. RMSEA assesses the degree of complexity in the model, and resulting values close to 0.06 indicate adequate model-data fit (Hu and Bentler 1999).

As the survey included the child's gender, the items comprising the three behaviour adjustments and the parental involvement were analysed by ANOVA to determine the effect of children's gender.

\section{Results}

\section{Descriptive statistics and normality}

Table 1 summarizes the descriptive statistics for the items in the survey. Using the data for further analysis in CFA and structural equations requires the normality of data. Further analysis reveals that both kurtosis and skewness values of all items in the survey are between \pm 2 . A kurtosis or skewness value near zero indicates a shape close to normal (Mardia 1970).

For the externalizing behaviour, the highest mean is observed for 'Talks back to adults when corrected' and 'threatens or bullies others'. The highest means for internalizing behaviour are 'Easily embarrassed' and 'Appears lonely'. For hyperactivity behaviour, the highest means are 'Fidgets and moves excessively' and 'Disturbs on-going activities'. The lowest scores for externalizing behaviour relate to 'Fights with others' and 'Argues with others'; the lowest scores for internalizing behaviour relate to 'Acts sad or depressed' and 'Shows anxiety about being with a group of children', and for hyperactivity behaviour, the lowest scores relate to 'Acts impulsively' and 'Interrupts conversations of others'. For parental involvement items, the highest scores are for 'Parents are more likely to visit their child's classroom' and 'Parents speak to teacher regularly'. The lowest scores relate to 'Parents support their children's learning at home' and 'Parents read more to their children at home'.

Table 2 reports the correlation coefficients between the items used in the survey of teachers. For the items in the three behaviour domains, all correlations are positive and significant. The correlations of items in the three behaviour domains with items in the parental involvement construct are all negative and significant. These correlations indicate that higher parental involvement leads to more positive outcomes in children's externalizing, internalizing and hyperactivity behaviours. All correlations are significant. Table 3 reports the correlation analysis of the composite scores of the three behaviour constructs and the parental involvement construct. The three behaviour constructs are correlated, with the highest being between internalizing and externalizing behaviours (0.930). All three behaviour constructs are negatively correlated with parental involvement, with all coefficients being significant. It should be noted here that it is also reasonable to assume that teacher responses regarding certain children's behaviours and their parents' 


\begin{tabular}{|c|c|c|c|c|c|c|c|c|c|c|c|c|c|c|c|c|c|c|c|c|c|c|c|c|}
\hline & A31 & A33 & A41 & A42 & A43 & A44 & A32 & A34 & A38 & A39 & A45 & A46 & A35 & A36 & A37 & A40 & A47 & A48 & B51 & B52 & B53 & B55 & B56 & B57 \\
\hline A31 & 1 & & & & & & & & & & & & & & & & & & & & & & & \\
\hline A33 & .56 & 1 & & & & & & & & & & & & & & & & & & & & & & \\
\hline A41 & .66 & .56 & 1 & & & & & & & & & & & & & & & & & & & & & \\
\hline A42 & .51 & .46 & .56 & 1 & & & & & & & & & & & & & & & & & & & & \\
\hline A43 & .57 & .47 & .69 & .45 & 1 & & & & & & & & & & & & & & & & & & & \\
\hline A44 & .70 & .64 & .70 & .50 & .60 & 1 & & & & & & & & & & & & & & & & & & \\
\hline A32 & .65 & .63 & .72 & .57 & .65 & .66 & 1 & & & & & & & & & & & & & & & & & \\
\hline A34 & .54 & .52 & .54 & .48 & .51 & .54 & .56 & 1 & & & & & & & & & & & & & & & & \\
\hline A38 & .61 & .57 & .69 & .52 & .51 & .72 & .63 & .52 & 1 & & & & & & & & & & & & & & & \\
\hline A39 & .59 & .53 & .66 & .52 & .54 & .60 & .60 & .46 & .55 & 1 & & & & & & & & & & & & & & \\
\hline A45 & .63 & .63 & .61 & .55 & .61 & .68 & .66 & .59 & .60 & .56 & 1 & & & & & & & & & & & & & \\
\hline A46 & .72 & .64 & .79 & .57 & .67 & .84 & .72 & .59 & .74 & .64 & .70 & 1 & & & & & & & & & & & & \\
\hline A35 & .63 & .53 & .64 & .57 & .55 & .55 & .63 & .52 & .56 & .52 & .65 & .66 & 1 & & & & & & & & & & & \\
\hline A36 & .57 & .55 & .64 & .44 & .54 & .59 & .61 & .45 & .51 & .61 & .50 & .65 & .50 & 1 & & & & & & & & & & \\
\hline A37 & .45 & .47 & .51 & .44 & .43 & .46 & .52 & .38 & .39 & .38 & .47 & .52 & .46 & .37 & 1 & & & & & & & & & \\
\hline $\mathrm{A} 40$ & .56 & .48 & .56 & .42 & .49 & .58 & .57 & .51 & .53 & .51 & .50 & .56 & .48 & .48 & .35 & 1 & & & & & & & & \\
\hline A47 & .60 & .57 & .64 & .40 & .53 & .63 & .61 & .52 & .56 & .52 & .61 & .66 & .53 & .53 & .38 & .51 & 1 & & & & & & & \\
\hline A48 & .51 & .40 & .59 & .41 & .47 & .52 & .54 & .39 & .49 & .48 & .42 & .60 & .51 & .41 & .38 & .44 & .39 & 1 & & & & & & \\
\hline B51 & -.23 & -.24 & -.20 & -.14 & -.28 & -.22 & -.21 & -.27 & -.25 & -.15 & -.28 & -.21 & -.21 & -.24 & -.05 & -.12 & -.18 & -.08 & 1 & & & & & \\
\hline B52 & -.55 & -.57 & -.56 & -.58 & -.51 & -.52 & -.59 & -.52 & -.53 & -.50 & -.60 & -.58 & -.60 & -.46 & -.36 & -.42 & -.51 & -.38 & .37 & 1 & & & & \\
\hline B53 & -.54 & -.52 & -.59 & -.44 & -.55 & -.62 & -.61 & -.55 & -.54 & -.40 & -.59 & -.71 & -.52 & -.44 & -.40 & -.44 & -.51 & -.40 & .29 & .60 & 1 & & & \\
\hline B55 & -.55 & -.60 & -.55 & -.54 & -.50 & -.59 & -.58 & -.58 & -.53 & -.48 & -.66 & -.61 & -.58 & -.48 & -.36 & -.42 & -.50 & -.32 & .43 & .80 & .75 & 1 & & \\
\hline B56 & -.39 & -.28 & -.36 & -.25 & -.36 & -.38 & -.37 & -.41 & -.26 & -.21 & -.41 & -.37 & -.33 & -.26 & -.23 & -.30 & -.28 & -.18 & .36 & .43 & .51 & .48 & 1 & \\
\hline B57 & -.40 & -.28 & -.40 & -.35 & -.29 & -.35 & -.42 & -.29 & -.42 & -.25 & -.40 & -.39 & -.41 & -.29 & -.19 & -.20 & -.27 & -.29 & .22 & .45 & .40 & .49 & .22 & 1 \\
\hline
\end{tabular}


Table 3 Correlation between the constructs in the study

\begin{tabular}{lllll}
\hline & Externalizing & Internalizing & Hyperactivity & Involvement \\
\hline Externalizing & 1 & & & \\
Internalizing & $0.930^{* *}$ & 1 & & \\
Hyperactivity & $0.893^{* *}$ & $0.883^{* *}$ & 1 & 1 \\
Involvement & $-0.673^{* *}$ & $-0.677^{* *}$ & $-0.575^{* *}$ & \\
\hline
\end{tabular}

* Significant at $(0.01)$

** Significant at $(0.001)$

involvement may not be totally independent of each other. It is not surprising that the two measures were correlated.

CFA of each behaviour construct and the parent involvement construct

Confirmatory factor analysis was conducted for the sub-domains of externalizing, internalizing and hyperactive behaviours as measures of adjustment to the KG-1 schooling by fitting the one-factor congeneric model to the data for each behaviour construct individually. The results indicate that all items are valid indicators of the three behaviour tendencies.

For the externalizing behaviour, the largest standard estimate relates to A41 (Argues with others, 0.86) and A44 (Has temper tantrums, 0.83). The fit statistics provide a $\chi^{2}$ of 24.68 with 9 degrees of freedom, with a $P$-value of 0.0018, RMSEA of 0.073, NFI of 0.987, CFI of 0.991 and GFI of 0.979. Results indicate that all six items - A31, A33, A41, A42, A43 and A44 - are valid indicators of externalizing behaviour and jointly contribute $93.6 \%$ of the variance to this measure of adjustment. In Margetts's (2005) study, only four items (A31, A41, A42 and A43) were valid indicators of externalizing behaviour that contributed to $95.1 \%$ of the variance.

For the internalizing behaviour, the largest standard estimates relate to A32 (Has low self-esteem, 0.97) and A34 (Appears lonely, 0.83). The fit statistics provide a $\chi^{2}$ of 10.31 with 9 degrees of freedom, with a P-value of 0.3262, RMSEA of 0.0193, NFI of 0.996, CFI of 0.999 and GFI of 0.991. Results indicate that all six items - A32, A34, A38, A39, A45 and A46 - are valid indicators of internalizing behaviour and jointly contribute $81.5 \%$ of the variance to this measure of adjustment. In Margetts's (2005) study, only four items (A32, A34, A38 and A46) were valid indicators of internalizing behaviour.

For the hyperactivity behaviour, the largest standard estimates relate to A36 (Interrupts conversations of others, 0.98) and A35 (Is easily distracted, 0.91). The fit statistics provide a $X^{2}$ of 13.843 with 9 degrees of freedom, a $P$-value of 0.1280 , RMSEA of 0.0371, NFI of 0.993, CFI of 0.998 and GFI of 0.989. Results indicate that all six items - A35, A36, A37, A40, A47 and A48 - are valid indicators of hyperactivity behaviour and jointly contribute $96.5 \%$ of the variance to this measure of adjustment. In Margetts's (2005) study, only four items (A35, A37, A40 and A48) were valid indicators of hyperactivity behaviour. They jointly accounted for $96.2 \%$ of the variance of this measure of adjustment.

The resulting fit statistics provide good evidence to confirm the validity of the measures used in Margetts's (2005) previous work.

The parent involvement construct with six items was also analysed by CFA. Results demonstrate that not all items are significant. The item 'B54: Parents highly involved in child education' was removed from further analyses. The largest standard estimate relates to 
'B55: parents speak to teacher regularly' (0.94) and 'B52: Parents more likely to visit their child's classroom' (0.85). They jointly accounted for $69.2 \%$ of the variance of this measure of adjustment. The fit statistics provide a Chi-square of 13.56 with 5 degrees of freedom, with a $P$-value of 0.01869 , RMSEA of 0.043 , NFI of 0.983 , CFI of 0.9901 and GFI of 0.981 .

\section{Structural equation model}

Figure 2 and Table 4 report results of the structural equation model. Good fit statistics are confirmed with a maximum likelihood ratio $\chi^{2}$ of 330.52 with 203 degrees of freedom, RMSEA of 0.0348 , NFI of 0.997 , CFI of 0.986 and GFI of 0.981 . Table 5 reports that three major paths exist in the structural model, the estimates and the level of significant of these estimates. All paths carry negative signs to indicate that parental involvement significantly reduces the tendencies for the three behaviour domains, with the greatest effect on externalizing behaviour (0.793).

The objective of the present study was, in a sense, to make a complex analysis of the factors affecting the three domains of behaviour. Byrne (2002) noted that, in a complex system, it is unclear what constitutes a factor and what serves as the dependent variable. To more clearly validate the structural equation model, the study conducted further analysis to examine whether the three behavioural constructs also affect the independent variables of parental involvement. This analysis explored, for example, the guarantees that the factors are not also reciprocally influenced by children's behaviour. Thus, could the level of behaviour features among children also have a contiguous effect on parental involvement? For that reason, the study applied another model to test various underlying structural designs. Figure 3 portrays the model tested by structural equations. Results provide satisfactory fit indexes with a $\chi^{2}$ of 655.788 (with 224 degrees of freedom), RMSEA of 0.0702, NFI of 0.974, CFI of 0.982 and GFI of 0.902. These results also demonstrate that parents know how their children might behave in KG-1 as they start their schooling. As a result, they try to be more involved as

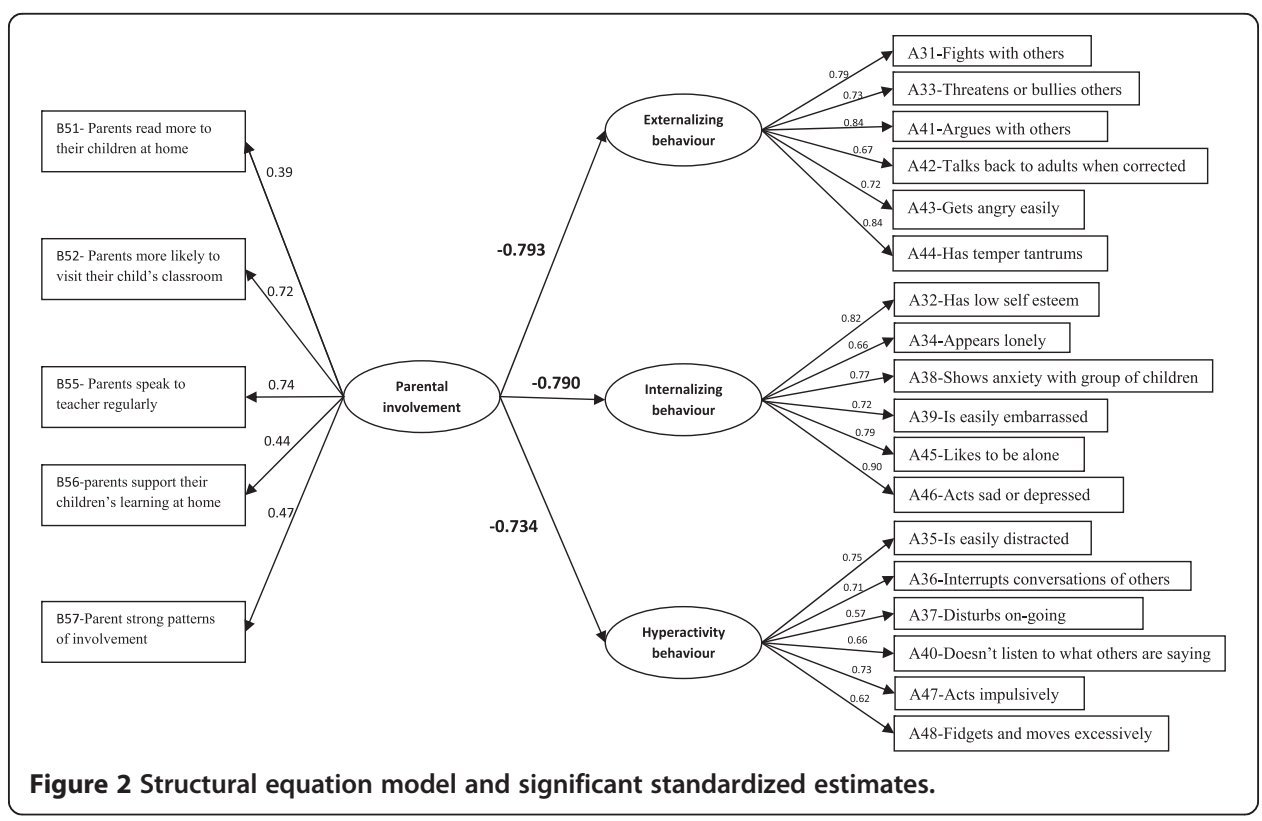


Table 4 SEM fit indices for the model

\begin{tabular}{|c|c|c|c|c|}
\hline & & Standardized estimates & $t$-value & $R^{2}$ \\
\hline \multicolumn{5}{|c|}{ Externalizing behaviour } \\
\hline A31. & Fights with others & 0.79 & 17.67 & 0.620 \\
\hline A33. & Threatens or bullies others & 0.73 & 16.07 & 0.529 \\
\hline A41. & Argues with others & 0.86 & 19.98 & 0.736 \\
\hline A42. & Talks back to adults when corrected & 0.66 & 14.37 & 0.441 \\
\hline A43. & Gets angry easily & 0.74 & 16.33 & 0.542 \\
\hline A44. & Has temper tantrums & 0.82 & 18.73 & 0.673 \\
\hline \multicolumn{5}{|c|}{ Internalizing behaviour } \\
\hline A32. & Has low self esteem & 0.88 & 22.15 & 0.688 \\
\hline A34. & Appears lonely & 0.68 & $15 / 47$ & 0.465 \\
\hline A38. & Shows anxiety being with a group of children & 0.77 & 18.32 & 0.592 \\
\hline A39. & Is easily embarrassed & 0.73 & 16.92 & 0.529 \\
\hline A45. & Likes to be alone & 0.81 & 19.65 & 0.651 \\
\hline A46. & Acts sad or depressed & 0.89 & 23.08 & 0.790 \\
\hline \multicolumn{5}{|c|}{ Hyperactivity behaviour } \\
\hline A35. & Is easily distracted & 0.74 & 16.18 & 0.564 \\
\hline A36. & Interrupts conversations of others & 0.71 & 14.55 & 0.499 \\
\hline A37. & Disturbs ongoing activities & 0.58 & 11.72 & 0.333 \\
\hline A40. & Doesn't listen to what others are saying & 0.66 & 13.48 & 0.434 \\
\hline A47. & Acts impulsively & 0.73 & 16.08 & 0.533 \\
\hline A48. & Fidgets and moves excessively & 0.63 & 12.82 & 0.395 \\
\hline \multicolumn{5}{|c|}{ Parental involvement } \\
\hline B51. & Parents read more to their children at home & 0.46 & 9.12 & 0.415 \\
\hline B52. & Parents more likely to visit their child's classroom & 0.48 & 9.44 & 0.477 \\
\hline B55. & Parents speak to teacher regularly & 0.91 & 20.79 & 0.834 \\
\hline B56. & parents support their children's learning at home & 0.54 & 10.91 & 0.494 \\
\hline B57. & Parent strong patterns of involvement & 0.54 & 10.95 & 0.596 \\
\hline
\end{tabular}

necessary. This finding is a major outcome from this examination. However, the original model in the study provided much improved fit indexes, as demonstrated earlier, indicating that the direction of influence is from parental involvement to the three behaviour domains.

\section{Child gender and the behaviour domain}

The analysis of variance (ANOVA) tests of all items in the three behaviour constructs and parental involvement construct for children's gender provide significant results for only four items of a total of 24 items. Thus, gender in general has little influence on the three behaviour domains or the degree of parental involvement. Table 6 reports the

Table 5 Structural equation paths

\begin{tabular}{lllll}
\hline Path from & Path to & Coefficient & $\boldsymbol{t}$-value & $\boldsymbol{R}^{\mathbf{2}}$ \\
\hline Parent involvement & Externalizing behaviour & -0.793 & -13.98 & 0.629 \\
Parent involvement & Internalizing behaviour & -0.790 & -14.56 & 0.624 \\
Parent involvement & Hyperactivity behaviour & -0.734 & -12.12 & 0.538 \\
\hline
\end{tabular}




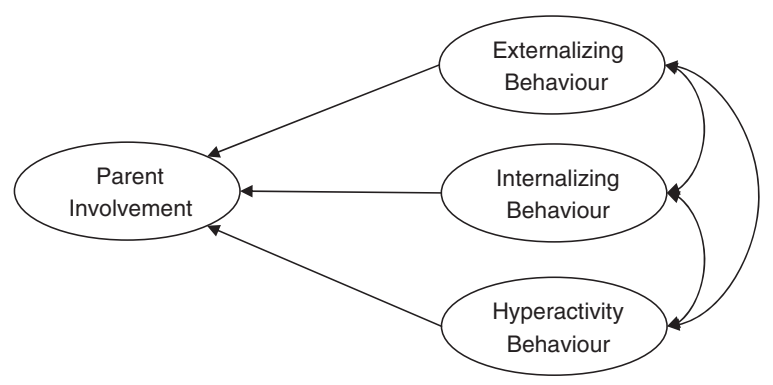

Figure 3 SEM model with reciprocal paths - model B.

results of the four significant items. Boys experience higher degrees of temper tantrums, embarrassments and acting sad or depressed. The mean scores also reveal that parents support their male children's learning at home more than that of their female children.

\section{Discussion}

The effect of parental involvement on the three behavioural constructs of children behaviour is apparent in this research by witnessing the negative standardized estimate signs of the three paths in the structural equation model. Such result is consistent with other studies of similar nature calling for a need for kindergarten teachers and the school to collaborate with parents (Pianta and Cox 1998; Hill and Craft 2003; Hoover-Dempsey and Sandler 1997).

By looking at the items comprising the three behaviour constructs of internalizing, externalizing and hyperactivity behaviours, the current research demonstrates that children in Abu Dhabi have moderate to serious problems transitioning to kindergarten. This result is consistent with research carried out in other Western countries too (Pianta and Cox 1998; Dougherty et al. 2011).

As other studies showed (Willerman 1979; Plomin 1990), results here show that what a child knows and how he or she behaves are measures of children's behaviour at school entry and can serve as indicators of how well families prepare children for school.

Table 6 Analysis of variance of items according to child gender

\begin{tabular}{llll}
\hline Construct & Items and means & $\boldsymbol{F}$ & Significance \\
\hline Externalizing & A44: Has temper tantrums & 5.015 & 0.026 \\
& Male: 2.85 & & \\
& Female: 2.56 & 11.331 & 0.001 \\
A39: Is easily embarrassed & & \\
Internalizing & Male: 3.59 & & \\
& Female: 3.11 & 5.591 & 0.019 \\
Internalizing & A46: Acts sad or depressed & & \\
& Male: 2.88 & & \\
Hyperactivity & Female: 2.54 & & \\
Parental involvement & None & & \\
& B56: Parents support their children's learning at home & 6.374 & \\
Male: 3.20 & & \\
\hline
\end{tabular}


For Abu Dhabi KG-1 children, the present study indicates behaviours that contribute to measures of externalizing, internalizing and hyperactivity behaviours and may impede children's adjustment to school. The study also demonstrates the effect of parental involvement with the child's schooling and the levels of these behaviours as perceived by the teachers. In addition, results reveal that the three behaviour constructs (indicators) are significantly affected by parent involvement. Teacher perception of children's performance is also a function of the three behaviour tendencies and parent involvement.

In her use of structural equation modelling, Margetts (2005) explored and explained direct, indirect and interdependent effects of observable variables. The use of structural equation model in the current study has assisted in identifying particular behaviours that contribute to the broader constructs of hyperactivity, internalizing and externalizing behaviours, for children attending KG schools across Abu Dhabi. The results of fitting the one-factor congeneric model to the data for each of the three behaviour constructs provide significant standard estimates of all items comprising the constructs (a total of 18 items or representing externalizing, internalizing and hyperactivity behaviours). Margetts (2005) found some of the indicators not to be significant. CFA of the sixindicator parental involvement construct identified only five significant drivers.

The Abu Dhabi study results provide more evidence of parent involvement's influence on behavioural adjustment to findings of recent studies conducted in other cultures (Margetts 2005; Drugli et al. 2011; Kirkhaug et al. 2013). The study stresses that an awareness of these observable behaviours can assist early childhood teachers and staff in kindergarten and the early years of schooling to identify children who may be at risk of not adjusting well to school. Many previous studies stress that teachers could benefit significantly from the early identification of the negative behaviours and that awareness could support them in identifying and fostering behaviours that may better support children's adjustment to school (Ladd and Price 1987; Pettit et al. 1997).

Consistent with other studies, results suggest that aggressive or externalizing behaviours are best identified through such responses such as 'Fights with others', 'Threatens or bullies others', 'Argues with others', 'Talks back to adults when corrected', 'Gets angry easily' and 'Has temper tantrums' (Caldwell and Pianta 1991). Results also suggest that internalizing behaviours are often associated with 'Has low self-esteem', 'Appears lonely', 'Shows anxiety about being with a group of children', 'Is easily embarrassed', 'Likes to be alone' and 'Acts sad or depressed' (Renwick 1984). The valid indicators of hyperactive behaviours include 'Is easily distracted', 'Interrupts conversations of others', 'Disturbs ongoing activities', 'Doesn't listen to what others are saying', 'Acts impulsively' and 'Fidgets and moves excessively' (Rydell 1989). It is these behaviours that are more likely to predict children having difficulty adjusting to school.

Results showed that children's gender in general has little influence on the three behaviour domains or the degree of parental involvement. However, boys experience higher degrees of temper tantrums, embarrassments and acting sad or depressed. These results are consistent with other researches of similar objectives (Stemmler et al. 2005; Williford et al. 2007). Similar with (Krishnan 2011), the higher mean scores for boys also reveal that parents support their male children's learning at home more than that of their female children.

Taken together with the challenges facing children as they commence school, parents and teachers play key roles in equipping children with the skills to better cope with 
transition difficulties. Both teachers and parents should work cooperatively to encourage and support children to interact with their peers and adults in positive ways. Both should support children in developing self-confidence. Children should be provided with opportunities to experience success when trying new things and coping with the unexpected (Margetts 2005; Catsambis 2001). Usually, such nurturance starts at home when parents give their budding school children consistent guidance and support in being responsible for controlling their feelings and behaving in acceptable and considerate ways without disturbing or hurting others, so that they are more likely to exhibit self-control (Hill and Craft 2003; Margetts 2003).

Many strategies can be implemented in KG-1 that could give children the opportunities to enhance their readiness capabilities for schooling. However, successful strategies require cooperation between parents and the school, especially teachers (Hornby and Witte 2010). Margetts (2003) suggests that children and parents frequently visiting the school prior to attending have significant effects. If the setting is familiar to them, children are more likely to adjust to new demands and expectations. The author notes that when children are prepared for making the transition to school, they gain self-confidence and are more likely to succeed.

Results are consistent with other research that suggests that through interactions with adults (parents and teachers) and peers (other students), young children develop self-concepts and self-esteem, improve emotional self-regulation and form their first friendships (Brooks-Gunn et al. 2003).

\section{Conclusions}

The adjustment to kindergarten can be a stressful time for children, teachers and parents. However, if teachers can facilitate more involvement and collaboration between parents and kindergarten teachers, it will be a smoother process. Parents need to try to find a developmentally appropriate class for their child by observing different classrooms and talking to teachers about educational philosophies. Both kindergarten teachers and parents can help the child with this important transition and adjustment.

Research demonstrates that children who begin to exhibit externalizing, internalizing or other types of negative behaviour in childhood have an increased likelihood of sustained patterns of similar behaviour across their lifespan and are at increased risk for developing long-term negative outcomes, including antisocial behaviour in adolescence and adulthood (Lycett et al. 2014; Silver et al. 2005; Broidy et al. 2003; Moffitt et al. 2002). The current Abu Dhabi study also stresses that the early awareness and understanding of those risks might offer much-needed information and support for the school and parents to deal with the situation constructively.

Margetts $(2005,2003)$ notes that problem behaviours in the early years, including extreme overactivity, inability to sit still, short attention span, emotional difficulties and negative attitude predict lower levels of academic achievement and progress and behaviour problems in adolescence. The present study also stresses that the availability of reliable tools to identify children at risk of difficulties is useful and can assist educators in easing these reactions, minimizing ongoing difficulties and adapting their own practices. Other researchers add that identifying and understanding the roles of both teachers and parents in helping children to adjust better to the school setting is of the highest importance (Fabian 2000a, 2000b; Margetts 2002). 
The most important contribution of the present study, especially for Abu Dhabi, is that the results may provide much-needed information concerning the role of parental involvement as it relates to the three domains of externalizing, internalizing and hyperactivity behaviours. More specifically, the construct of parental involvement with its detailed items could enable decision makers in ADEC to target specific strategies to improve both parental involvement and the three behaviour domains. The study enjoyed fairly high response rates (number of schools contacted and number of responses). It should also be mentioned that few other studies have focused on the relations between drivers of child behavioural reactions when joining kindergarten and parental involvement in the school.

Creasey et al. (1995) note that aggressive children are likely to manifest anxious and restless behaviours or to intensify them during the transition to schooling. As a result, the challenges facing children as they start their KG experience should be managed deliberately. These children need to acquire the skills to better cope with transition difficulties. Both parents and school educators can encourage and support children in interacting with their peers and adults in positive ways and to cope with frustrations and restrictions. More effective parental involvement could support children in developing self-confidence and provide opportunities to experience success when trying new things and coping with the unexpected. Margetts (2005) adds that when children are given consistent guidance and support in being responsible for controlling their feelings and behaving in acceptable and considerate ways without disturbing or hurting others, they are more likely to exhibit self-control.

The present study's findings reveal that different forms of parental involvement in early schooling are significantly associated with enhancing children's behavioural adjustments to school. Higher involvement is associated with children having fewer internalizing, externalizing or hyperactivity behavioural problems or related symptoms in school. Therefore, schools should be aware that in designing educational policies and educational interventions, decision makers should be more aware of the influence of parental involvement in children's success. Schools should re-examine their policies regarding parental involvement and develop an educational strategy in which family and teachers assume mutual responsibility for children's outcomes, especially with regard to adjustment.

\section{Implications for Abu Dhabi}

For Abu Dhabi specifically, the results confirm that parents play a critical role in their children's education. Their involvement heavily influences a child's behaviour outcomes and, in turn, their academic performance and self-esteem. Focus group interviews of KG-1 teachers continue to struggle with how to involve parents - and how to hold them accountable - especially when they do not, cannot or will not participate in their child's education. Some teachers noted that ADEC should implement aggressive strategies to change the expectations at home and change the family environment. However, the situation is grave. ADEC's 2012 teacher survey confirms that teachers see parental involvement as the major challenge. Teachers assigned relatively lowest scores to the items related to degree of "parental involvement" on the survey. Many open-ended notes reflected frustration that parents are not sufficiently involved. In 2013, ADEC prepared a guideline booklet for parents with KG 
children. The booklet gathered a variety of international research outcomes that stressed that students with parents who are involved in their school tend to have fewer behavioural problems and better academic performance and are more likely to complete high school than students whose parents are not involved in their school. The good news is that parental involvement has grown in certain grade levels. According to four measures that ADEC tracked in the 2013 teacher survey, parents in KG-1 and KG-2 exhibited the highest parental involvement.

ADEC has established a team of 'ADEC Ambassadors' to visit homes in 2014 to stress that continued parental involvement ensures that the parents serve as an advocate in monitoring their child's academic progress, attendance and quality of education. ADEC will depend on those ambassadors to disseminate the culture of parental involvement in schools. The ambassadors will pilot a programme in ten KG schools across the Emirate of Abu Dhabi. They will engage in school programmes that will train the most involved parents first, who will become 'parenting partners' and teach the skills to other parents. The objective is to build effective partnerships between home and school. One candidate ambassador noted that they could not control what goes on at home but could help the parents in how they behave at home. ADEC has also prepared a strategy for educating parent's employers. Employers also should consider allowing more flexibility so that during working hours parents can attend a school play, a parent-teacher meeting or do volunteer work.

The results of the Abu Dhabi study may apply to schools in general and to educational institutions that attempt to encourage parental involvement in particular. Results verify that parental involvement is a major component of school life, especially for KG students. ADEC encourages many preschools in Abu Dhabi to implement various strategies that help children to have opportunities to visit the school prior to attending. Similar strategies, with the support of parents, might help children to become familiar with school settings. It is believed that children are thus more likely to adjust to new demands and expectations.

The idea is to work with parents to help children become more prepared for making the transition to school by ensuring that they gain self-confidence. When children start their KG experience, schools urge parents to help their children become more familiar with the school prior to attending. ADEC provides many professional development programmes to schools to familiarize them in conducting many transition activities for children, assuming that they help children to experience fewer problem behaviours than do children who attend schools with a limited number of transition opportunities prior to attendance.

To assist parents, many public KG and preschool teachers are encouraged to arrange visits to the school and take parents along on the kindergarten field trip. They can ask for children to be paired with other kindergarten children while parents meet with the teacher and other school staff. Schools are also encouraged to inform parents that prior to school opening, children become excited about going to kindergarten but simultaneously feel apprehensive. These attempts are consistent with other empirical research that notes that the presence of familiar settings (i.e., school environment and playmates) was associated with children adjusting better to school and demonstrating higher levels of appropriate behaviours (Howes 1988; Margetts 2003). 


\section{Study limitations and future directions}

The study focused on KG-1 public school children only. As a result, the sample may not fully represent all Abu Dhabi KG-1 school children. School participation was voluntary, which may also restrict the generalizability of our findings. The findings should be interpreted with caution and require further exploration in more representative samples. In addition, because of time constraints and other requirements, children with special needs were not included in the present study.

The study relied on only teachers' reporting of parental involvement, and the perspectives of parents may differ from those of the teachers. However, despite the lack of parent reports, Jeynes (2003) notes that teacher ratings are expected to adequately reflect parental involvement.

The present study did not use other variables that might reflect student achievement. Most of the reviewed literature has consistently demonstrated the importance of parental involvement in facilitating children's academic achievement (Jeynes 2003, 2007; Shute et al. 2007). Future studies might also consider the effect of both parental involvement and the three behaviour domains on student outcomes.

Research demonstrates that both parental involvement and student achievement dimensions are affected by other strong predictors such as certain family sociodemographic characteristics, including income, ethnicity, number of children, parental style, parents' level of education, parents' marital and parental perception of their role and their levels of confidence in fulfilling it (Deslandes et al. 1997; Deslandes et al. 1998; Deslandes et al. 1999; Georgiou 1995; Sputa and Paulson 1995; Alizadeh et al. 2011; Roche et al. 2007; Kim and Rohner 2002). Future studies should consider adding these variables to the model.

Extending the study to KG-2 and beyond as a longitudinal study might also help in designing better policies and strategies for better planning and decision-making. The availability of the National Identity Card's (NIC) common number in Abu Dhabi should be utilized to follow up on student achievement and progress from year to year through school and college and as they enter the real-life work environment. Future studies should utilize the availability of the common NIC in follow-up studies of similar natures.

No doubt that the study's design and findings could have been better if parental involvement data were collected from both parents and teachers. However, such studies with more comprehensive surveys might require teachers to be more familiar with related parental activities and might also require parent participation. In addition, Future studies might also attempt to conceptualize parent or family involvement along other dimensions that include more detailed items about home-based involvement, school-based involvement, and home-school communication (Epstein 1995; Fantuzzo et al. 2000). For that purpose, other instruments such as the Family Involvement Questionnaire-Elementary Version (FIQ-E; Manz et al. 2004) or similar instruments may be utilized. The instrument should reflect a more multidimensional selfreporting scale measuring family involvement. Home-based involvement should reflect educational activities in which family members actively participate in supporting a child's learning at home. Examples of such activities might include helping with homework and creating a space for learning activities. School-based involvement activities should include parents' active participation in educational activities typically 
undertaken at school, such as volunteering in the classroom or assisting on class field trips. Home-school communication might include interpersonal interactions and connections between family members and teachers, such as attending parent-teacher conferences.

\section{Competing interests}

The authors declare that they have no competing interests.

\section{Authors' contributions}

MB initiated the study conception and design and the analysis and interpretation of data; AAQ provided the critical revision of the research paper; both AR and GY worked on acquisition of data and drafting the manuscript. All authors read and approved the final manuscript.

Received: 3 June 2014 Accepted: 14 October 2014

Published online: 28 October 2014

\section{References}

Alizadeh, S, Abu Talib, M, Rohani, A, \& Mariani, M. (2011). Relationship between parenting style and children's behavior problems. Asian Social Science, 7(12), 195-200.

Becker, S, Luebbe, A, \& Langberg, J. (2012). Co-occurring mental health problems and peer functioning among youth with attention-deficit/hyperactivity disorder: a review and recommendations for future research. Clinical Child and Family Psychology Review, 15(4), 279-302.

Behar, L, \& Stringfield, S. (1974). A behaviour rating scale for the pre-school child. Developmental Psychology, 10(5), 601-610.

Belsky, J, \& MacKinnon, C. (1994). Transition to school: developmental trajectories and school experiences. Early Education and Development, 5(2), 106-119.

Broidy, L, Nagin, D, Tremblay, R, Bates, J, Brame, B, \& Dodge, K. (2003). Developmental trajectories of childhood disruptive behaviours and adolescent delinquency: a six-site, cross-national study. Developmental Psychology, $39(2), 222-245$.

Brooks-Gunn, J, Fuligni, AS, \& Berlin, $L$ (Eds.). (2003). Early child development in the 21st century: profiles of current research initiatives. New York: Teachers College Press.

Byrne, BM. (2002). Structural equation modeling with AMOS. Mahwah: NJ Erlbaum.

Caldwell, S, \& Pianta, R. (1991). A measure of young children's problem and competence behaviours: the early school behavior scale. Journal of Psycho educational Assessment, 9(1), 32-44.

California Department of Education. (2000). Prekindergarten learning and development guidelines. Sacramento, CA.

Caspi, A, Henry, B, McGee, R, Moffitt, T, \& Silva, P. (1995). Temperamental origins of child and adolescent behaviour problems: from age 3 to age 15. Child Development, 66(1), 55-68.

Catsambis, S. (2001). Expanding knowledge of parental involvement in children's secondary education: connections with high schools seniors. Social Psychology of Education, 5(2), 149-177.

Clancy, S, Simpson, L, \& Howard, P. (2001). Mutual trust and respect. In S Dockett \& B Perry (Eds.), Beginning school together: sharing strengths. Watson: Australian Early Childhood Association Inc.

Cowan, P, Cowan, C, Shulz, M, \& Henning, G. (1994). Prebirth to preschool family factors in children's adaptation to kindergarten. In R Parke \& S Kellart (Eds.), Exploring family relationships with other social contexts (pp. 75-114). Hillsdale, NJ: Lawrence Erlbaum Associates.

Creasey, G, Mitts, N, \& Catanzaro, S. (1995). Associations among daily hassles, coping, and behavioral problems in non-referred kindergarteners. Journal of Clinical Child Psychology, 24(3), 311-319.

Dearing, E, Kreider, H, Simpkins, S, \& Weiss, HB. (2006). Family involvement in school and low-income children's literacy: longitudinal associations between and within families. Journal of Educational Psychology, 98(4), 653-664.

Desforges, C, \& Abouchaar, A. (2003). The impact of parental involvement, parental support and family education on pupil achievement and adjustment: a literature review. DfES Research Report, 433. http://bgfl.org/bgfl/custom/ files_uploaded/uploaded_resources/18617/desforges.pdf.

Deslandes, R, Royer, E, Turcotte, D, \& Bertrand, R. (1997). School achievement at the secondary level: influence of parenting style and parent involvement in schooling. McGill Journal of Education, 32, 191-208.

Deslandes, R, Bouchard, P, \& St-Amant, JC. (1998). Family variables as predictors of school achievement: sex differences in Quebec adolescents. Canadian Journal of Education, 23(4), 390-404.

Deslandes, R, Potvin, P, \& Leclerc, D. (1999). Family characteristics as predictors of school achievement: parental involvement as a mediator. MCGILL Journal of Education, 34(2), 135-153.

Dockett, S, Perry, R, \& Tracey, D. (1997). Getting ready for school. Brisbane: Paper presented at the Australian Association for Research in Education Annual Conference. December, 1997.

Dougherty, LR, Bufferd, SJ, Carlson, GA, Dyson, M, Olino, TM, Durbin, CE, \& Klein, DN. (2011). Preschoolers' observed temperament and psychiatric disorders assessed with a parent diagnostic interview. Journal of Clinical Child \& Adolescent Psychology, 40, 295-306.

Driessen, G, Smit, F, \& Sleegers, P. (2005). Parental involvement and educational achievement. British Educational Research Journal, 31(4), 509-532.

Drugli, MB, Klökner, C, \& Larsson, B. (2011). Do demographic factors, school functioning, and quality of student-teacher relationships as rated by teachers predict internalizing and externalizing problems among Norwegian school children? Evaluation \& Research in Education, 24(4), 243-254.

Duckworth, K. (2008). Influences on attainment in primary school interactions between child, family and school contexts. DCSF Research Brief RB, 04. https://www.gov.uk/government/uploads/system/uploads/attachment_data/ file/222317/DCSF-WBL-04-08FR.pdf 
Dunlop, AW. (2000). Perspectives on the child as a learner: should educators' views of preschool and primary children differ? (Paper presented at the EECERA 10th European Conference on Quality in Early Childhood Education, London). August 29-September 1, 2000.

Ekblad, S. (1990). The children's behaviour questionnaire for completion by parents and teachers in a Chinese sample. Journal of Child Psychology and Psychiatry, 31, 775-791.

Epstein, J. (1995). School/family/community partnerships. Phi Delta Kappan, 76(9), 701-712.

Epstein, J. (2001). School, family and community partnerships: preparing educators and improving schools. Boulder, CO: Westview Press.

Fabian, H. (2000a). A seamless transition. Paper presented at the EECERA 10th European Conference on Quality in Early Childhood Education, London. August 29-September 1, 2000.

Fabian, H. (2000b). Empowering children for transitions. Paper presented at the EECERA 10th European Conference on Quality in Early Childhood Education, London. August 29-September 1, 2000.

Fantuzzo, J, Tighe, E, \& Childs, S. (2000). Family involvement questionnaire: a multivariate assessment of family participation in early childhood education. Journal of Educational Psychology, 92(2), 367-376.

Freeman, EB, \& Hatch, JA. (1989). What schools expect young children to know and do: An analysis of kindergarten report cards. Elementary Sch J, 89(5), 595-605.

Georgiou, S. (1995). Achievement attributions of sixth grade children and their parents. Educational Psychology, 19(4), 399-412.

Gresham, F, \& Elliott, S. (1990). Social Skills Rating System Manual. Circle Pines: American Guidance Service.

Hattie, J. (2009). Visible learning: a synthesis of over 800 meta-analyses relating to achievement. London, UK: Routledge.

Hill, N, \& Craft, S. (2003). Parent-school involvement and school performance: mediated pathways among socioeconomically comparable African American and Euro-American families. Journal of Educational Psychology, 95(1), 74-83.

Hoover-Dempsey, KV, \& Sandler, M. (1997). Why do parents become involved in their children's education? Review of Educational Research, 67(1), 3-42.

Hornby, G, \& Witte, C. (2010). Parent involvement in rural elementary schools in New Zealand: a survey. Journal of Child and Family Studies, 19(6), 771-777.

Howes, C. (1988). Peer Interaction of Young Children. Monographs of the Society for Research in Child Development 53 (2. Serial No. 217). In K Maxwell \& C Eller (Eds.), (1994, September) Children's Transition to Kindergarten, Young Children.

$\mathrm{Hu}, \mathrm{L}, \&$ Bentler, PM. (1999). Cutoff criteria for fit indexes in covariance structure analysis: conventional criteria versus new alternatives. Structural Equation Modeling, 6, 1-55.

Jeynes, W. (2003). The effects of black and Hispanic twelfth graders living in intact families and being religious on their academic achievement. Urban Education, 38(1), 35-57.

Jeynes, W. (2007). The relationship between parental involvement and urban secondary school student academic achievement. Urban Education, 42(1), 82-110.

Jöreskog, K, \& Sörbom, D. (1989). LISREL7: a guide to the program and applications (2nd ed.). Chicago: SPSS Inc.

Kienig, A. (2000). Transitions in early childhood (Paper presented at the EECERA $10^{\text {th }}$ European Conference on Quality in Early Childhood Education, London). August 29-September 1, 2000.

Kim, K, \& Rohner, R. (2002). Parental warmth, control and involvement in schooling: predicting academic achievement among Korean American adolescents. Journal of Cross Cultural Psychology, 33(2), 127-140.

Kirkhaug, B, Druglia, M, Klöckner, C, \& Mørchc, W. (2013). Association between parental involvement in school and child conduct, social, and internalizing problems: teacher report. Educational Research and Evaluation, 19(4), 346-361.

Knudsen-Lindauer, S, \& Harris, K. (1989). Priorities for kindergarten curricula: views of parents and teachers. Journal of Research in Childhood Education, 4(1), 51-61.

Krishnan, V. (2011). Teachers' assessment of preschoolers' social and emotional competence: does sex of children matter in developmental outcomes? (Proceedings of the World Academy of Science, Engineering and Technology, Year 7, Issue 79, 2011, pp. 1622-1632). www.waset.org.

Ladd, J, \& Price, J. (1987). Predicting children's social and school adjustment following the transition from preschool to kindergarten. Child Development, 58(5), 1168-1189.

Lycett, K, Sciberras, E, Mensah, F, \& Hiscock, H. (2014). Behavioral sleep problems and internalizing and externalizing comorbidities in children with attention-deficit/hyperactivity disorder. European Child \& Adolescent Psychiatry. doi:10.1007/s00787-014-0530-2.

Machen, SM, Wilson, JD, \& Notar, CE. (2005). Parental involvement in the classroom. Journal of Instructional Psychology, 32(1), 13-16.

Manz, P, Fantuzzo, J, \& Power, T. (2004). Multidimensional assessment of family involvement among urban, elementary students. Journal of School Psychology, 42(6), 461-475.

Mardia, KV. (1970). Measures of multivariate skewness and kurtosis with applications. Biometrika, 57(3), 519-530.

Margetts, K. (2002). Transition to school—complexity and diversity. European Early Childhood Education Research Journal, 10(2), 103-114.

Margetts, K. (2003). Children bring more to school than their backpacks: starting school down under. Journal of European Early Childhood Education Research Monograph, 1, 5-14.

Margetts, K. (2005). Children's adjustment to the first year of schooling: indicators of hyperactivity, internalizing and externalizing behaviors. International Journal of Transitions in Childhood, I, 36-44.

McClelland, M, \& Morrison, F. (2003). The emergence of learning-related social skills in preschool children. Early Childhood Research Quarterly, 18(2), 206-224.

Merrell, C, \& Tymms, PB. (2001). Inattention, hyperactivity and impulsiveness: their impact on academic achievement and progress. British Journal of Educational Psychology, 71(1), 43-56.

Moffitt, T, Caspi, A, Harrington, H, \& Milne, B. (2002). Males on the life-course-persistent and adolescence-limited antisocial pathways: follow-up at age 26 years. Development and Psychopathology, 14(1), 179-207.

Moser, J, Emily Durbin, C, Patrick, C, \& Schmidt, N. (2014). Combining neural and behavioral indicators in the assessment of internalizing psychopathology in children and adolescents. Journal of Clinical Child \& Adolescent Psychology, 1-12. doi:10.1080/15374416.2013.865191.

Muller, C. (1998). Gender differences in parental involvement and adolescents' mathematics achievement. Sociology of Education, 71(4), 336-356. 
Nokali, NEE, Bachman, HJ, \& Votruba-Drzal, E. (2010). Parent involvement and children's academic and social development in elementary school. Child Development, 81(3), 988-1005.

Pettit, S, Bates, J, \& Dodge, K. (1997). Supportive parenting, ecological context, and children's adjustment: a seven-year longitudinal study. Child Development, 68(5), 908-923.

Pianta, R, \& Cox, M. (1998). Kindergarten transitions. Teachers: 48\% of children have transition problems (NCEDL Spotlights Series, No. 1). Chapel Hill, NC: National Center for Early Development \& Learning.

Plomin, R. (1990). Nature and nurture: an introduction to human behavioral genetics. Pacific Grove, CA: Brooks/Cole Publishing Co.

Prior, M. (1996). Learning and behavioral difficulties: implications for intervention. Free Public Lecture, The University of Melbourne. September 30, 1996.

Prior, M, Smart, MA, Sanson, A, \& Oberklaid, F. (1993). Sex differences in psychological adjustment from infancy to 8 years. Journal of the American Academy of Child \& Adolescent Psychiatry, 32(2), 291.304

Reid, MJ, Webster-Stratton, C, \& Hammond, M. (2007). Enhancing a classroom social competence and problem-solving curriculum by offering parent training to families of moderate-to high-risk elementary school children. Journal of Clinical Child and Adolescent Psychology, 36(4), 605-620.

Renwick, M. (1984). To school at five: the transition from home or preschool to school. Wellington: NZCER.

Riedinger, S. (1997). Even start: facilitating transitions to kindergarten (Dept. of Education). Washington, DC: Planning and Evaluation Service.

Roche, K, Ensminger, M, \& Cherlin, A. (2007). Parenting style and adolescent outcomes among African and Latino families living in low income. Journal of Family Issues, 11(23), 882-909.

Rogers, M, Theule, J, Ryan, B, Adams, G, \& Keating, L. (2009). Parental involvement and children's school achievementevidence for mediating processes. Canadian Journal of School Psychology, 24(1), 34-57.

Rydell, AM. (1989). School adjustment, school performance and peer relations among first-graders in a Swedish suburban area. Scandinavian Journal of Psychology, 30(4), 284-295.

Schwartz, D, McFadyen-Ketchum, S, Dodge, K, Pettit, S, \& Bates, J. (1999). Early behavior problems as a predictor of later peer group victimization: moderators and mediators in the pathways of social risk. Journal of Abnormal Child Psychology, 27(3), 191-201.

Semke, C, Garbacz, A, Kwon, K, Sheridan, S, \& Woods, K. (2010). Family involvement for children with disruptive behaviors: the role of parenting stress and motivational beliefs. Journal of School Psychology, 48(4), 293-312.

Shute, V, Hansen, E, \& Underwood, J. (2007). A review of the relationship between parental involvement and secondary school students' academic achievement. Education Research International, 20, 1-10.

Silver, R, Measelle, J, Armstrong, J, \& Essex, M. (2005). Trajectories of classroom externalizing behavior: contributions of child characteristics, family characteristics, and the teacher-child relationship during the school transition. Journal of School Psychology, 43(1), 39-60.

Sputa, C, \& Paulson, S. (1995). Birth order and family size: influences on adolescents' achievement and related parenting behaviors. Psychology Reports, 76, 43-51.

Stemmler, M, Lösel, F, Beelmann, A, Jaursch, S, \& Zenkert, B. (2005). Child problem behavior in kindergarten and in primary school: a comparison between prediction configural frequency analysis and multiple regressions. Psychology Science, 47(3/4), 467-478.

Taylor, J. (1998). Life at six: life chances and beginning school. Fitzroy: Brotherhood of St. Laurence.

Weiss, HB, Bouffard, SM, Bridglall, BL, \& Gordon, EW. (2009). Reframing family involvement in education: supporting families to support educational equity (Equity Matters: Research Review No. 5).

Willerman, L. (1979). The psychology of individual and group differences. San Francisco: W. H. Freeman and Company.

Williford, AP, Calkins, SD, \& Keane, SP. (2007). Predicting change in parenting stress across early childhood: child and maternal factors. Journal of Abnormal Child Psychology, 35(2), 251-263.

doi:10.1007/s40723-014-0003-6

Cite this article as: Badri et al:: The causal relationship between parental involvement and children's behavioural adjustment to KG-1 schooling. International Journal of Child Care and Education Policy 2014 8:3.

\section{Submit your manuscript to a SpringerOpen ${ }^{\circ}$ journal and benefit from:}

- Convenient online submission

- Rigorous peer review

- Immediate publication on acceptance

- Open access: articles freely available online

- High visibility within the field

- Retaining the copyright to your article

Submit your next manuscript at $\gg$ springeropen.com 